\title{
Anticardiolipin antibodies in concurrent poststreptococcal glomerulonephritis and autoimmune hemolytic anemia: A case report
}

\author{
Ying-liang Gong M.D. ${ }^{a}$ and Yu-feng Li Ph.D. ${ }^{a}$
}

\begin{abstract}
We present a case of acute post-streptococcal glomerulonephritis (APSGN) with autoimmune hemolytic anemia (AIHA). Along with the classic findings of APSGN, the patient had a positive direct antiglobulin test and an anticardiolipin antibody without any typical clinical manifestations of antiphospholipid syndrome (APS). This case raises questions of the relationship between Streptococcus and the development of autoimmune hemolytic anemia in children. Our case highlights the possibility that the streptococcal infections in this patient might be responsible for her anemia, either in setting of underlying antiphospholipid antibodies, or in having triggered the development of pathogenic antibodies, which subsequently leads to the clinical evolution of hemolysis. It is presumed that in our case, the anticardiolipin antibody induced by streptococcal infection may play a direct role in the clinical evolution of AIHA.

Key words: child, glomerulonephritis, autoimmune hemolytic anemia, anticardiolipin antibody
\end{abstract}

http: / / dx.doi.org/10.5546/ aap.2018.eng.e288

To cite: Gong Y, Li Y. Anticardiolipin antibodies in concurrent poststreptococcal glomerulonephritis and autoimmune hemolytic anemia: A case report. Arch Argent Pediatr 2018;116(2):e288-e291.

\section{INTRODUCTION}

Poststreptococcal glomerulonephritis is the most common cause of glomerulonephritis in childhood $^{1}$. In rare cases patients may adopt a rapidly progressive form or may result in anemia, hypertension and renal dysfunction in the longterm follow-up. However, severe anemia is not common in patients with APSGN and not adequately explained in some patients.

a. Department of Pedi-Nephrology, Xinhua Hospital affiliated to Shanghai Jiaotong University School of Medicine, Shanghai, China.

\section{E-mail address:}

Ying-liang Gong, M.D.: elainegongcn@outlook.com

Funding: None.

Conflict of interest: None.

Received: 4-25-2017

Accepted: 9-19-2017
Anticardiolipin antibodies belong to the class of antiphospholipid antibodies and appear in relation to autoimmune processes included but do not restricted to antiphospholipid syndrome and systemic lupus erythematosus. They have rarely described in acute poststreptococcal glomerulonephritis. Their significance in renal diseases has not yet been established. In our case, we describe a child presented with the nephrotic syndrome, severe autoimmune hemolytic anemia and anticardiolipin antibody. This association has never previously been described, and we speculate that anticardiolipin antibodies maybe more common in patients with APSGN than is currently appreciated.

\section{CASE REPORT}

A 10-year-old girl developed pallor, anorexia, fatigability and amber urine following a nonfebrile illness with pharyngitis (treated with a 3-day course of azithromycin) for 2 days. She came to Shanghai Xinhua Hospital and was admitted to the department of nephrology that day.

She denied any history of unexplained bruising, blood in the stool or abnormal menstruation. Previous medical history was unremarkable. She did not have sickle cell disease or any previous history suggestive of thalassemia. Her vital signs were normal and blood pressure was $116 / 82 \mathrm{mmHg}\left(\mathrm{P}_{95}\right)$. Physical examination only revealed pale complexion, cadaverous eyelid conjunctiva and armour bed, but otherwise was normal. In Table 1 the main clinical and laboratory data of the patient during the admission are shown.

In summary, she was found to have severe normochromic anemia $(5.6 \mathrm{mg} / \mathrm{dl}$, reference range $11-15 \mathrm{mg} / \mathrm{dl}$ ), hematuria and proteinuria, hypocomplementemia and a high antistreptolysin O (ASO) titer. The direct antiglobulin test (DAT) was positive with anti-C3. Her antinuclear antibody (ANA) and anti-doublestranded DNA antibody (anti-ds-DNA) were negative. Her medication including antibiotics and symptomatic treatments like blood 
transfusion were given. Methylprednisolone was followed $2 \mathrm{mg}$ per kilogram weight intravenously on the $3^{\text {th }}$ day of administration for AIHA.

However, on the 5th day of her hospitalization, her hemoglobin recovered to normal while she developed oliguria, periorbital and pedal edema. Her blood pressure was $130 / 84 \mathrm{mmHg}\left(>\mathrm{P}_{99}\right)$ at the onset of edema. Further laboratory tests showed hypoalbuminemia, high cholesterol and positive anticardiolipin (aCL) antibody IgM. Ultrasound revealed mild unilateral pleural effusion. Due to diagnostic and/or prognostic reasons, a renal biopsy was done. Light microscopy (Figure 1) of the renal biopsy showed hypercellular, which included proliferating mesangial and end othelial cells and mild infiltration by mononuclear leukocytes. Of 46 glomeruli, null had crescent formation. Immunofluorescence revealed prominent deposition of $\mathrm{C} 3$ along the mesangium; IgG and IgA were stained along the capillary wall. Electron microscopy identified numerous dense deposits in the subepithelial space of the glomerular basement membrane. The histology was compatible with post-infectious glomerulonephritis.

Her hemoglobin level stabilized at $12.0 \mathrm{~g} / \mathrm{L}$ after the 8 days of hospitalization. Subsequently, her DAT was negative and C3 complement level was normal by 8 weeks after admission. In the following 2 year after discharge, her anticardiolipin antibodies remain positive but no signs of prolonged fever, thrombocytopenia or any other symptoms of antiphospholipid syndrome or systemic lupus erythematosus were observed.

\section{DISCUSSION}

We describe a child presented with a constellation of signs and symptoms consisting of severe anemia, nephrotic syndrome, serological evidence of a recent streptococcal infection, and a decreased serum C3 level which subsequently normalized within 8 weeks. The patient had a positive anticardiolipin IgM that persisting positive in the one-year follow up without any typical clinical manifestations of thrombotic diseases. A renal biopsy in the patient showed classic histology of post-infectious glomerulonephritis. The clinical picture was typical for APSGN.

FIGURE 1. Light microscopy of the renal biopsy

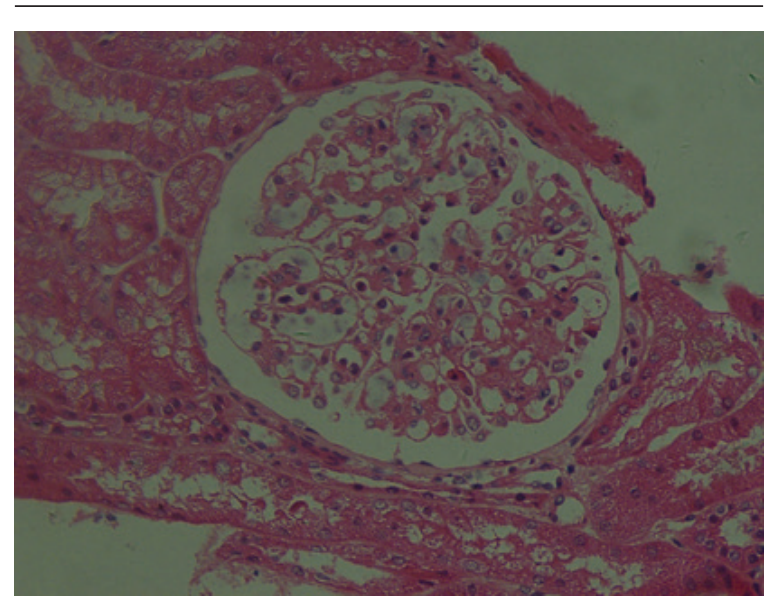

Diffuse inflammatory cellular infiltration and mesangial hypercellularity (hematoxylin and eosin staining: original magnification X 200).

TABLE 1. Key laboratory results after admission

\begin{tabular}{|c|c|c|c|c|c|}
\hline & $\begin{array}{c}\text { Hemoglobin } \\
(\mathrm{g} / \mathrm{L})\end{array}$ & $\begin{array}{c}\text { Reticulocyte } \\
\text { count }(\%)\end{array}$ & $\begin{array}{l}\text { Anticardiolipin } \\
\text { antibody (IgM) }\end{array}$ & $\begin{array}{c}\text { Complement } \\
\text { C3 (g/L) }\end{array}$ & $\begin{array}{c}\text { Complement } \\
\mathrm{C} 4(\mathrm{~g} / \mathrm{L})\end{array}$ \\
\hline Reference range & $110-150$ & $0.5-1.5$ & negative & $0.9-1.8$ & $0.1-0.4$ \\
\hline Initial & 56 & 5.25 & + & 0.04 & 0.18 \\
\hline $5^{\text {th }}$ Day & 89 & / & / & / & l \\
\hline 8 Weeks & 134 & 1.3 & l & 0.87 & 0.22 \\
\hline 4 Month & 117 & l & + & 1.49 & 0.3 \\
\hline 6 Month & 135 & 1 & l & / & / \\
\hline 9 Month & 123 & 1.55 & \pm & 1.48 & 0.27 \\
\hline 16 Month & 134 & l & \pm & 1.45 & 0.25 \\
\hline 24 Month & 120 & / & / & / & l \\
\hline
\end{tabular}

The hemoglobin level of the patient was abnormal at the onset and was stabilized at $12.0 \mathrm{~g} / \mathrm{L}$ after 8-day treatment. Her C3 complement level was normal within 8 weeks after admission. Her anticardiolipin antibodies remain positive in the one-year follow-up. 
ACLs belong to the class of antiphospholipid antibodies (APA) and appear in relation to autoimmune processes included but do not restricted to antiphospholipid syndrome and systemic lupus erythematosus. There were cases published reporting APA with uncomplicated post-infectious glomerulonephritis. ${ }^{2,3}$ Case like our patient with a prolonged aCL IgM was never reported in APSGN complicated by AIHA. Surprisingly the occurrence of anticardiolipin antibody during the acute and convalescence periods of APSGN is very high, ${ }^{2}$ showing an incidence of $44 \%$ with abnormal IgG aCL titers. Even in healthy children, anticardiolipin antibodies have been reported to be positive in up to $25 \% .{ }^{4}$ It is believed aCL antibodies appear in response to many acute infections, especially in childhood infections. ${ }^{5}$ In a review, $20 \%$ of patients with $\mathrm{HCV}, 49.75 \%$ with $\mathrm{HIV}$, one quarter with $\mathrm{HBV}$ and other bacterial infections including streptococcal infection have elevated serum aCL level. Worden and his team injected streptococcal M protein antibody probe mAb10F5 into rats and examined for the presence of antiphospholipid. ${ }^{6}$ Results showed a significant increase of antiphospholipid antibody two weeks after injection demonstrating Streptococcus is responsible for the generation of antiphospholipid antibodies. These evidences highlight the possibility that the streptococcal infection in our patient might had triggered the development of her aCL IgM.

Severe hemolytic autoimmune anemia like the case we report is not first found in patients with post-streptococcal acute glomerulonephritis. Larry et al. described three semblable cases, two of which had a cold-reacting anti-I autoantibody. ${ }^{7}$ A 10-year-old boy had anuric renal failure and profound hemolytic anemia. His elevated ASO titer and kidney biopsy were consistent with APSGN. ${ }^{8}$ The severity of the anemia could not be easily explained by hemodilution of APSGN. It was reported $90 \%$ of their APSGN patients were anemic, but hemodilution was rarely the sole explanation. ${ }^{9}$ Little was known about the underlying pathogenic mechanism of AIHA in patients with APSGN.

Some evidences suggested aCLs may play a direct role in the pathogenesis of hemolytic anemia in certain diseases. Sthoeger et al. found aCLs act as anti-RBC autoantibodies in the process of AIHA in some SLE patients. ${ }^{10}$ Arvieux et al. reported evidence suggesting that $\operatorname{IgG}$ and $\operatorname{IgM}$ antiphospholipid antibodies caused hemolytic anemia in a patient with some clinical features of systemic lupus erythematosus. ${ }^{11}$ Del Papa et al. reported the association of hemolytic anemia and an IgG anti-phospholipid antibody in a patient with a primary antiphospholipid syndrome. ${ }^{12}$ Jamie and his team studied by Elisa the presence of antiphospholipid antibodies in sera from AIHA patients and none-autoimmune hemolysis. Results suggested that antiphospholipid antibodies were present in a substantial number of patients with AIHA and this response did not seem to be secondary to the hemolysis proper. ${ }^{13}$ It is presumed that in our case, the anticardiolipin antibody induced by streptococcal infection may play a direct role in the clinical evolution of AIHA.

APA has been reported to be associated with glomerular thrombosis in lupus nephropathy with different interpretations about their role in the pathogenesis of the renal disease. ${ }^{14}$ Whether APA has a pathogenic role in the setting of renal injury in APSGN remains to be determined. These antibodies have been hypothesized to have the potential to exacerbate inflammation-mediated tissue injury..$^{15}$ However, Ardiles et al. found no difference of degree of renal injury, glomerular abnormalities in urine and creatinine levels in clinical follow-up between aCL-positive patients and aCL-negative patients with APSGN. ${ }^{2}$

It is considered that aCL can be associated with a thrombotic risk if persistently elevated. None of the cases published as well as our patient showed risk of developing thrombotic diseases in their follow-up. Through this case, we speculate that aCL maybe more common in patients with APSGN than is currently appreciated and the presence of aCL antibodies in APSGN maybe a marginal immunological phenomenon triggered by Streptococcus infection which has no predictive value to the later onset of other thrombotic diseases.

\section{REFERENCES}

1. Pan CG. Glomerulonephritis in childhood. Curr Opin Pediatr 1997;9(2):154-9.

2. Ardiles L, Ramirez P, Moya P, et al. Anticardiolipin Antibodies in Acute Poststreptococcal Glomerulonephritis and Streptococcal Impetigo. Nephron 1999;83(1):47-52.

3. Leifer D, Butani L. Implications of antiphospholipid and antineutrophilic Cytoplasmic Antibodies in the Context of postinfectious glomerulonephritis. Case Rep Med 2017;2017:9896210.

4. Siemens HJ, GutscheS, BrücknerS, et al. Antiphospholipid antibodies in children without and in adults with and without thrombophilia. Thromb Res 2000;98(4):241-7.

5. Avcin T, ToplakN. Antiphospholipid antibodies in response to infection. Curr Rheumatol Rep 2007;9(3):212-8. 
6. Kelly-WordenM,ManningM,Gebhard R, etal.Streptococcal M Protein Epitope 10F5 Generates Antiphospholipid Antibodies. Biophys J 2016;110(3):79a-80a.

7. Greenbaum LA, Kerlin BA, Van Why S, et al. Concurrent poststreptococcal glomerulonephritis and autoimmune hemolytic anemia. Pediatr Nephrol 2003;18(12):1301-3.

8. Cachat F, Dunsmore K, Tufro A. Concomitant anuric post-streptococcal glomerulonephritis and autoimmune hemolytic anemia. Eur J Pediatr 2003;162(7-8):552-3.

9. Lau KK, Hastings MC, Delos Santos N, et al. A Child with Post-streptococcal Acute Glomerulonephritis Complicated by Coombs Positive Autoimmune Hemolytic Anemia. Internet J Radiol 2007;4(1).

10. Sthoeger Z, Sthoeger D, Green L, et al. The role of anticardiolipin autoantibodies in the pathogenesis of autoimmune hemolytic anemia in systemic lupus erythematosus. J Rheumatol 1993;20(12):2058-61.
11. Arvieux J, Schweizer B, Roussel B, et al. Autoimmune hemolytic anaemia due to anti-phospholipid antibodies. Vox Sang 1991;61(3):190-5.

12. DelPapa N, Meroni PL, Barcellini W, etal. Antiphospholipid antibodies cross-reacting with erythrocyte membranes. A case report. Clin Exp Rheumatol 1992;10(4):395-9.

13. Guzmán J, Cabral AR, Cabiedes J, et al. Antiphospholipid antibodies in patients with idiopathic autoimmune haemolytic anemia. Autoimmunity 1994;18(1):51-6.

14. Frampton G, Hicks J, Cameron JS. Significance of antiphospholipid antibodies in patients with lupus nephritis. Kidney Int 1991;39(6):1225-31.

15. Willis R, Gonzalez EB, Brasier AR. The journey of antiphospholipid antibodies from cellular activation to antphospholipid syndrome. Curr Rheumatol Rep 2015;17(3):16. 